\title{
AN OPEN AUDIOMETRY SERVICE IN A MILITARY HOSPITAL
}

\author{
Dr. R. A. GREENWOOD, M.R.C.P., L.R.C.P.
}

Lieutenant-Colonel T. M. O. MORRIS, M.B., F.R.C.S., D.L.O., R.A.M.C.

Miss ANNE M. POWELL, Cambridge Military Hospital, Aldershot.

SUMMARY : An improvised hospital audiometry service open to all medical practitioners in an area is described and the need for and advantages of such a service are discussed. The tests carried out and results obtained during a nine month period are also discussed and details are given of the cause of deafness in 29 recruits who were found to be unfit for service from a total of 860 examined.

\section{Introduction}

In an occupation with such a noise hazard as the armed forces, audiometry should have an important role in helping to maintain that vital part of the health and well being of its members, namely the hearing.

To make audiometric testing in this context more widely available in the Aldershot area the audiometric facilities of this hospital have been offered as an open service for the past 2 years, to military and civilian practitioners.

\section{Organisation and method}

Doctors were invited to refer suitable patients for audiometry when they sought information on the hearing level alone without requiring an otologist's opinion but it was suggested that those with a hearing loss of over $20 \mathrm{~dB}$ should be referred for such opinion.

Appointments were made by telephone and the test was normally carried out on the same day or within twenty-four hours.

The service was not suitable for children under 4 years of age as the assessment of their hearing requires more sophisticated testing.

One of us was available during working hours for testing but when possible tésts were performed at times when there were no clinics being held. A Peters Clinical Audiometer S.P.D.S. was used with the subject in a silent booth and air conduction (A.C.) only was tested, unless bone conduction testing was asked for by the doctor or thought to be particularly indicated by the audiometrician.

At the request of medical officers of some recruit training depots the service was extended to provide screening tests for their intakes. For groups of over twenty recruits the audiometrician would arrange to go to the depots with an Amplivox Clinical audiometer so that the testing could be integrated into the medical examination and immunisation programme. The depots concerned were asked to provide a reasonably quiet room with an electrical supply and the 'silencing' of ambient noise under these circumstances depended on the attenuating properties of the head set. 
Patients were referred by both service and civilian practitioners and consisted mainly of children, serving personnel and recruits. Civilian employees of the War Department in occupations with a noise hazard, such as an electrical generating station, were also tested at intervals.

\section{School Children}

\section{The need}

Audiometry in the Army has previously only been available outside otology clinics for screening tests on school children and, a more widespread availability beyond this narrow limit is essential for the proper conservation of hearing. The importance alone of the early diagnosis of the 'glue ear syndrome' in children cannot be too strongly emphasised in relation to their progress at school and a hearing loss on audiometry is the only reliable diagnostic criterion for this condition. The routine school hearing tests are performed at very infrequent intervals and there will be occasions in the interim periods when a child's doctor will suspect deafness and wish to confirm this by audiometry.

\section{Service personnel}

For medical officers having the care of serving personnel the usefulness of an open audiometry service is two-fold:-

(a) The confirmation of a hearing loss found on free field voice tests in the medical centre and,

(b) The detection of early high-tone hearing loss in those exposed to noise which will not be apparent on voice tests.

The former hearing loss should be recognised in the subject's Pulheems assessment so that situations in which his hearing loss might be a danger to himself and others can be avoided.

Those with a high-tone hearing loss can be instructed in the importance of protecting their hearing and the very necessary regular follow up instituted.

\section{Results}

Table I shows the total numbers tested and the numbers referred for further examination in a nine-month period of 1969. A total of 1011 recruits were tested in the same period of which 860 from two recruit training depots were followed up. Of this number 29 (3.39 per cent) were found unfit for service (Table II).

The Pulheems assessments at Table II were in accordance with those given by Cable and Morris* except that those with a mild high-tone loss were recorded as requiring follow up but the degree of $\mathrm{H}$ remained as 2 .

The cause of deafness in the 29 recruits found unfit for service was investigated clinically, audiometrically and radiographically. Where a specific cause is shown under perceptive deafness the diagnosis could only be made by indirect evidence, as in all suspected cases of acoustic trauma; these patients had a high-tone hearing loss and a definite history of exposure to the noise indicated. High-tone loss was present in 12 of the 28 but no relevant history was elicited to account for this loss in three patients.

\footnotetext{
* Paper at Page 3 of this issue.
} 
Table I

Audiometric tests carried out in a nine-month period

\begin{tabular}{l|c|c}
\hline \multicolumn{1}{c|}{ Patients } & Number & Hearing loss over 20 dB \\
\hline Children & 162 & 30 \\
Serving personnel & 105 & 36 \\
Others & 43 & 25 \\
\hline Totals & 310 & $91(29.3$ per cent $)$ \\
Recruits & 1011 & $29^{*}$ \\
\hline Grand total & 1321 & - \\
\hline
\end{tabular}

* Below entry standards.

Table II

Cause of deafness in 29 (3.9 per cent) recruits found unfit for service of 860 examined and followed up

\begin{tabular}{|c|c|c|c|c|c|}
\hline Type of deafness & Cause & Number & Type of deafness & Cause & Number \\
\hline $\begin{array}{l}\text { Conductive } \\
\qquad .\end{array}$ & $\begin{array}{l}\text { Perforation } \\
\text { Others }\end{array}$ & $\begin{array}{l}5 \\
2\end{array}$ & Perceptive & $\begin{array}{l}\text { Unknown } \\
\text { Shooting } \\
\text { Pop music } \\
\text { Occupational } \\
\text { Head injury }\end{array}$ & $\begin{array}{r}11 \\
4 \\
3 \\
2 \\
2\end{array}$ \\
\hline Total $\ldots$ & $\therefore$ & 7 & Total & . & 22 \\
\hline
\end{tabular}

Of the four ascribed to shooting, three had been using a twelve-bore shot gun and the fourth .22 rifles on an indoor range; none had worn any form of ear protection.

All three attributed to 'pop music' were active participants in "groups" using electronic amplification.

The two cases of occupational deafness were the result of employment in a 'machine shop' and as a "silk weaver'.

There were three patients with profound unilateral hearing loss and two with profound bilateral hearing loss of over $70 \mathrm{~dB}$.

It will be noted in Table II that five patients had a perforation of a tympanic membrane with a discharging ear.

\section{Comment}

The testing of recruits was performed before the clinical assessment by the medical officer and it should be stressed that on estimate 1 per cent would have been rejected on clinical grounds at the initial examination or during training so that the true percentage of. recruits brought to medical board as a result of audiometry would be nearer 2 per cent.

The advantages of screening audiometry for recruits are three-fold:-

(a) the detection of early high-tone loss not apparent on free field voice tests so that follow up can be instituted;

(b) the provision of a base line audiometric record before exposure to noise in training. 
(c) as an indicator of aural disease which might be missed on clinical examination.

The importance of the first two of these will be increased when high-tone loss becomes liable for compensation under the Industrial Diseases Act.

Clinically detectable deafness and active aural disease are not uncommonly missed on pre service examinations and audiometry does indicate those that require particularly close clinical scrutiny.

The recruit training depot is not the ideal place for audiometry as the recruit will already have been passed fit at a clinical examination and given up his employment so that considerable inconvenience is caused if aural disease leading to discharge is discovered at this stage. The test should form part of the initial recruit medical examination with a box for recording the result on the medical examination report (F.Med 1) on entry.

Audiometry has not received the acceptance it deserves in service medicine as an indispensible instrument in the investigation and preservation of the serviceman's hearing, largely because the findings have not been interpreted in relation to function. The discovery of small degrees of hearing loss has sometimes led to downgrading when this is functionally not justified.

This hospital audiometry service merely anticipates the time when the medical examination rooms in every recruiting centre, training centre and unit are equipped with an audiometer.

Results of testing carried out at 2 training depots without any form of silencing for ambient noise other than head phones and performed at a speed of 50 per hour were found to be very close to those obtained under clinic conditions. The head phones are most effective in cutting out high frequency ambient noises and the attenuation of the head phones used with the Peter's Audiometer is of the order of $30-40 \mathrm{~dB}$ at frequencies between 2 and 8,000 c.p.s.

Although this audiometry service was not designed as a clinical study but grew with the demands of those using it, it is hoped that this retrospective study may stimulate the wider introduction of such a scheme.

\section{The Mitchiner Medal}

The Council of the Royal College of Surgeons of England, at their meeting on 12th November 1970 approved the award of the Mitchiner Medal for 1971 to Colonel J. H. H. Oliver, T.D., Q.H.S., M.R.C.S., L.R.C.P., R.A.M.C. (T.A.V.R.), Officer Commanding 202 (Midland) General Hospital, R.A.M.C. (V.).

We extend our sincere congratulations to Colonel Oliver on this signal honour.

Since it was instituted in 1953, the medal has previously been awarded on one occasion only to a Territorial Officer. 